\title{
Gamification Analysis for Motivation and Engagement Using Running Apps
}

\author{
Nia Karlina \\ Visual Communication Design \\ Bina Nusantara University \\ Jakarta, Indonesia \\ Nia.Karlina@binus.ac.id
}

\author{
Arsa Widitiarsa Utoyo \\ Visual Communication Design \\ Bina Nusantara University \\ Jakarta, Indonesia \\ Arsa_w@binus.ac.id
}

\author{
Emanuel Himawan Saptaputra \\ Visual Communication Design \\ Bina Nusantara University \\ Jakarta, Indonesia \\ emanuel@binus.edu
}

\begin{abstract}
Gamification is the application of game features, mainly elements of video games, in a context not related to the game in order to promote motivation and commitment to learning. The application of gamification in a pedagogical context provides some remedy for many people who feel alienated from traditional teaching methods. The use of gamification could provide a partial solution to the decrease in the motivation and commitment of the students that the user faces today. Specifically, the younger environment could benefit greatly from gamification not only for its enjoyment but also for a healthy life. This critical analysis of gamification literature wants to be part of a sequence on the effect of gamification on motivation and commitment. A methodology proposed in the study of the effects of gamification in motivation and commitment, as well as an empirical study, consists of a smartphone application that provides tracking and gamification elements. While the control arm consists of on an application designed identically only with the characteristics of tracking health information. The proposal will be made among young people who use applications on the day off from cars in Jakarta.
\end{abstract}

Keywords-gamification, application, running, healthy

\section{INTRODUCTION}

The new movement to create effect not to related to games through an application of role-playing games and role- playing games that make the game fun, such as points, levels, ranking, results, fields of competition and prizes in call Gamification. The idea created by the New Games Movement in the United States. UU Gamification derived and developed. The gamification is pleasant and reaches the user's voluntary participation by offering methods to solve fun problems. The advantage of Gamification is that it rewards the achievement of the action towards the goal and the task. Elements such as points, leveling and classification stimulate internal and external motivations and maintain voluntary participation. Gamification is spreading rapidly as the most important conference and gamification in San Francisco in January 2011. Base on the M2 Research, the gamification market will increase from \$ 522 million in 2013 to \$ 2.83 billion in 2016 . Gamification methods attempt to take benefit of people's natural needs for competition, success, status, self-expression, altruism and closure. The approach of central gamification is a reward for players who perform the desired tasks. The types of rewards include points, badges or performance levels when player compiling a progress bar and the user with a virtual currency. Contest is another element of the games that can be used in gamification. Making rewards for performing tasks visible to other players or providing rankings is a way to encourage players to compete. Another approach to gamification is to make existing activities more similar to games. Some of the techniques used in this approach include adding important options that include a tutorial, increasing the challenge and adding narration. Although the term "gamification" was coined in 2002 by Nick Pelling, a programmer and inventor born in Britain, it did not gain popularity until 2010. Even before the term began to be used, other fields that took elements of video games were common; For example, some scientific visualization works adapt elements of videogames. Forbes blogger also retroactively marked Charles Coonradt, who founded the consultancy The Game of Labor in 1973 and in 1984 wrote a book with the same name of "Grandfather Gamification". The term "gamification" began to spread widely in 2010 , in a more specific sense it refers to the integration of the social / reward aspects of gaming software. The technique attracted the attention of venture capitalists, one of whom said he considered gamification to be the most promising area of the game. Another noted that half of all companies seeking financing for consumer software applications mention the design of the game in their presentations. Several researchers consider that gamification is closely related to previous work on the adaptation of game design elements and techniques to contexts not related to the game. Investigating human-computer interaction using elements derived from the game for motivation and interface design, Nelson argues the need for a connection with the Soviet concept of socialist competence as the American trend of "fun at work". Fuchs emphasizes that gamification could be driven by new forms of brilliant interfaces.

The gamification of the conference also built the simulation with retroactive effects, for example, Will Wright, game designer SimCity 1989, was the main speaker of the Gamification summit 2013 conference. In addition to the companies with the technique, more companies and platforms were created. gamification. In October 2007, Bunchball, supported by Adobe Systems Incorporated, was the first company to provide gaming mechanics such as the Infinity Dunder Mifflin service, the community site for the NBC television network The Office. Bunchball customers have included Playboy, Chiquita, Bravo and The USA Network. In June 2009 the Seattle-based BigDoor startup was founded, which provides gamification technology to websites that do not 
use games. Badgeville was launched at the end of 2010 and raised \$ 15 million in venture capital funds in its first year of business; provides gamification services to a large number of customers.

Smart phones are on the rise. The subscriptions to smartphones in 2014 were estimated at 2,700 million euro, with a forecast of 6,100 million euro for 2020. Equipped with a powerful processor, a high-resolution screen and a large memory capacity, smartphones offer a wide range of features for their users, such as mobile Internet, banking and e-mail services, as well as GPS navigation. As a result, the smartphone has assumed a central role in most of our modern lives. Applications are certainly popular. As of September 2014, the iTunes store offers an incredible amount of over 1.3 million different applications. By 2016, it is expected to download over 44 billion applications (International Association for the Wireless Telecommunications Industry, 2011, quoted in Cowan et al, 2012) [1]. Rival companies like Google have been quick to continue with their app store. Google offers its applications on the Google Play Store with a list of over 1.5 million different applications, starting in December 2014 [2]. The applications of health and physical activity are of particular interest. These applications focus on improving the health of their users. The number of mHealth applications that have been published has reached over 100,000 applications in 2014 (Research2guidance, 2014).

Fox (2010) [3] states that nearly 1 in 10 smartphone users downloaded a health and fitness related application. In fact, fitness applications are the majority of mHealth applications. Over $30 \%$ of all applications included in sections Medicine and Health Apple App Store and Google Play are trackers or guides of exercises. The mHealth application market has made significant progress during the industry promotion cycle. Revenue from the market reached $\$ 2.4$ billion in 2013 and is expected to increase to $\$ 26$ billion by the end of 2017 . In the last two years, mHealth's perception has become increasingly business-oriented. In other words, the mHealth application market has already entered the marketing phase [4].

\section{EASE OF USE}

Our study focuses on a certain type of MHealth health and fitness applications: running applications. These applications can be downloaded to the user's phone and help while doing cardio activity. The popularity of these applications is undoubtedly that applications like Nike + and Runkeeper have been downloaded more than 20 million times. For the broker, the added benefit of the application is that it tracks a myriad of variables: speed, distance, time, number of calories burned. In combination with body equipment, you can even monitor your heart rate. In addition, it allows the user to see the path they have taken and offers audio comments. The ability to collect health-related information in real-time offers a way to offer instant reminders and comments just-in-time. For example, users can immediately receive feedback on their performance or when they need to reduce speed / acceleration. Another advantage is the ability of the user to train their online community. By combining applications running with social networks, users can interact with other people, share information and encourage each other. In addition, some running applications offer specific training programs while storing all information in the application, allowing the user to keep track of their progress.

Most of the research so far has focused only on efficacy [5], accuracy [6], privacy risk and the scientific basis of health and fitness applications [7]. Surprisingly, there is little research on drivers and the motivation to use these applications. However, it is obvious that the reasons why people use a running application can be very different. You can use a running application simply to get ride statistics, the pleasure of tracing your career, sharing your career with friends, getting in touch with the community in general or staying motivated to keep running. To better understand why some people stop using a running application, while others support and adopt the running application in their lifestyle, these drivers should be examined carefully. Furthermore, the prolonged behavior was also influenced by other psychosocial variables. First, the theory of self-determination proposes that a more selfdetermined behavior (that is, when someone acts for the intrinsic pleasure derived from that activity) leads to positive behavior (ie, sustainable behavior)

[8] and physiological results. In fact, it has been found that the motivation is predictive of changes in the level of exercise in the school setting [9]. Secondly, it was discovered that differences in personality characteristics are associated with the use of smartphones and applications [10].

Based on these results and the limited number of studies that combine motivation and personality with the use of the application, we have chosen to include these variables in this study as additional drivers. It is evident that there is a considerable research gap around running applications. Our study aims to fill this gap and gain a deep understanding of what drives people to use a running application. Specifically, we try to understand which aspects of the application the main drivers are to engage people significantly and increase the likelihood of using the application. In this sense, we base our research on Jahn and Kunz [11] and use the model of uses and gamification to examine three types of controllers: contentoriented (ie, using an application running for their content), oriented to relationships (ie using an application running for social reasons) and oriented to themselves (ie using a running application to promote themselves). Furthermore, we want to examine whether the personality characteristics and the type of career goals set by a person have a connection with the use of a running application.

As a result, to the current we contribute scientific literature that PEOPLE push by establishing what to use app that in Execution, in that on them affect mode use of the SAME app and your IOC to be connected to the brand loyalty of eating. Threes, we provide one of the values due to Fronti Pratico also on. From the point of view of Public Health, obtaining one of the best Driver Understanding of the use of an App running, WE CAN Design will have application in Execution mode in which more people spend using it and then exercising it. They have studies that do not detect the main activity of the Fourth Risk Factor for premature death (World Health Organization, 2015a) [12]. However, the Duration of Physical Activities required THESE to reduce MUST be not necessarily longlasting risks. In Effects, the World Health Organization 
reported that Participation in only 150 Minutes of physical activity Moderate week EVERYDAY Reduces the risk of ischemic heart disease by $30 \%$, the risk of diabetes and $27 \%$ of cancer Risk of breast and colon 21-25\% [13].

From a marketing point of view, you can apply in Execution Be a new one for Companies mode Establish a Brand-Brand relationship. One on the grown-up Debate Activity and of Trademarks and Social Media Companies In fact, more and more Marketing Practitioners are focusing on building a "Brand Community" that is not a bounded geography from the community and on socially-based customer relationships among the proponents of a brand. The companies that good manage to create and execute their customers have an advantage compared to their competitors, I because applications of high educational debts offer marks one of the users of involvement and one on the attitude positive impact in the comparisons of the Brand [14]. Which have the use SECTOR of THESE Confirmed brand application has a positive impact increases interest for the brand and also of brand category products. This and Organized Thesis eat follows. First of all, Examples on the model we provide one of use SECTOR and this Studio for adopted gamification, followed by is a brief overview regarding literature Our drivers (Content, Report and Self- Orientation). Come on said, we have a model to increase the fourth type of a driver that could have an impact on the intensity of use of the SECTOR and on the commitment. Include THESE Psychosocial drivers perceived salutation, motivation and personality. We have formulated hypothesis Otto Based on your THESE constructs. Finally, we report the RESULTS of the Nostro studio. We conclude with a discussion of our discoveries, the limits of our search for theroads and research for the future.

III. DESIGN ELEMENTS OF GAMIFICATION People use a running application because it provides feedback on execution, such as heart rate, execution speed, and time / distance execution. In this way, the information provided by the application benefits a person during its execution, as it allows them to control their speed and heart rate and adjust their performance accordingly. Research often mentions this biofeedback as one of the most powerful means of facilitating self-regulation learning. In fact, it has been found that biofeedback is effective for reducing the anxiety of athletic performance, as well as for increasing muscle strength, reducing pain and fatigue. In addition, the app also benefits a person outside their training, since it allows them to monitor their progress. The running applications offer the user two types of interaction. First of all, it allows the user to connect and share their workouts via Facebook or Twitter with friends and other online colleagues. Research in social networks recognizes that cultivating and maintaining relationships with others is a great motivation for using a social networking site. In fact, people tend to join social networks to satisfy a need for belonging and are motivated to participate in content creation activities to satisfy their desire for social interaction and from the point of view of marketing, running applications help a company to create a community of brands. These are places where people who admire a brand can socialize with each other and with the brand itself, in a context provided by the brand [15].

\section{A. Content}

From a functional point of view, people use a running app because it provides them with feedback about their run, such as heart rate, running speed and time/distance ran. In this way, the information given by the app benefits a person during his run, since it enables them to monitor their speed and heart rate and adjust their run accordingly. Research often mentions this biofeedback as one of the most powerful means for facilitating the learning of self-regulation. Indeed, biofeedback has been found to be effective in reducing athletic performance anxiety, as well as increasing muscle strength, reducing pain and fatigue. Furthermore, the app benefits a person outside of their workout too, as it allows them to monitor their progress.

\section{B. Self-ecpression}

People can also decide to use a running app because they expect it will impact their image or status. In this case, the ability to track your runs and share your best runs with friends and peers serves as a powerful incentive to keep using a running app. By doing this, the users attempt to convey a certain positive image of themselves. This behavior is explained by the self-presentation theory [16], a framework to explain motivations for sharing content online. The theory stipulates that people can use a variety of strategies to impress others and influence the perception of their image. For example, by sharing their runs with others, they aim to increase their social attractiveness by highlighting their running achievements. Spillers and Asimakopoulos found that most runners are indeed interested in sharing small goals with their friends, while they usually want to share a milestone with a broader audience. Similarly, Peluchette and Karl have found that Facebook users use their profiles to send out a more positive picture of them. Provide your cybernetic space or allow avatars. Also, use cyber space to provide an area in which to express your opinion. People can also decide to use a running application because they expect it to influence their image or status. In this case, the ability to follow your careers and share the best careers with friends and colleagues is a powerful incentive to continue using a running application. In this way, users try to convey a certain positive image of themselves. This behavior is explained by the self-presentation theory, a structure to explain the motivations for sharing online content. The theory states that people can use a variety of strategies to impress others and influence the perception of their image. For example, by sharing their careers with others, they aim to increase their social attractiveness by highlighting the results of their careers. Spillers and Asimakopoulos (2014) [17] found that most brokers are interested in sharing small goals with their friends, while they generally want to share a milestone with awider audience.

\section{Reward}

Every user can provide their mileage or virtual goods based on the level of achievement of the movement that already have. If not, drive towards the growth of the avatar or the purchase of the item as an insightful means for a virtual space of the rate of increase of the level of achievement of the activity during the previous period of activity. At this time, be sure to increase loyalty to activities by rewarding participants immediately for the activity. In the event that the digital device is not in use, be 
sure to place a stickers or badge. Perceived health refers to a person's perception of health in general, and health does not only mean the absence of disease or injury, but also (Statistics Canada, 2014) physical, mental and social well-being. It has long been established that sports contribution has a substantial direct effect on professed health [18], with participation and exercise directly affecting self-esteem, even when other variables are controlled [19]. However, from a more hedonic point of view, we can assume people also use a running app because they simply enjoy using it when running. Although the exact definition of fun is rather elusive, there is general agreement in sport literature that the role of fun is a key aspect in sport participation. 'Having fun' is one of the most frequent reasons young athletes participate in sport.

\section{Status}

The participants who have level, conditional on the level of achievement of the activity, assign a level to the activists. And as was done in the development of guilds for associates in the game, invest in providing attributes of exclusive service groups that limit the amount allowed for the membership of the leisure activity group to recognize their status.

\section{E. Competition}

Specify mileage or any virtual goods based on the level of achievement of the movement. If not, drive towards the growth of the avatar or the purchase of the item as a reflective means for a virtual space of the rate of increase of the level of achievement of the activity during the previous period of activity. At this time, be sure to increase loyalty to activities by rewarding participants immediately for the activity. In the event that the digital device is not in use, be sure to place a stickers or badge.

\section{F. Motivation}

Research on motivation and sports has been refined since the proliferation of the self- determination theory, which distinguishes various types of motivation. The selfdetermination theory proposes that motivation is multidimensional and resides along a continuum of selfdetermination ranging from being not motivated (i.e. when someone is not motivated to act) through extrinsic motivation (i.e. when a person acts in response to external cues) to intrinsic motivation (i.e. when someone acts for the inherent pleasure derived from that activity) [20]. In recent years, this continuum has been expanded on to reveal autonomous and controlled motivation, both consisting of two separate sorts of motivation. Autonomous motivation encompasses both intrinsic motivation and identified regulation. The first involves doing an activity because one gets pleasure from the task itself, or from completing the task. We speak of identified regulation when a person has identified with the importance of a certain behavior and recognizes the beneficial effects of adopting the behavior. Controlled motivation includes external regulation, where one's behavior is a function of external rewards or punishments, and introjected regulation, where the action has only been internalized partially. The main motivational driver for behavior with this type of motivation is guilt, shame or worry.

\section{G. Personalty}

Interestingly, there has been some research on the association between smartphone use and personality. The most widely used psychological model to describe human personality is the five-factor model, more commonly named the "Big 5". These 5 broad factors - extraversion, agreeableness, conscientiousness, openness to experience and neuroticism - represent individual differences of thoughts, feelings and behavior. Tthe researchers explored predictors of app use in a large representative South Korean Sample. Although socio- demographic factors were by far the greatest prophet of smartphone use, individual modifications in personality were found to be associated with smartphone and application use. Extraversion was connected with an improved possibility of using a smartphone. Extraverts similarly place more emphasis on the communication features of a smartphone [21] and may adopt more quickly to novel technologies and influence others in doing the same since extraversion islinked to opinion leadership [22].

\section{H. Participation}

To reiterate, the uses and gratification model stipulates that if a running app manages to satisfy the various needs a runner has, this should lead to a higher approach to the running app. However, this approach can be defined in two ways. First of all, since it fulfills his needs, the user can simply decide to use the running app more often. In this manner, there would just be an increase in his usage intensity of the app. However, the user can also engage with the running app in a different, more distinct way. The user can create a meaningful relationship with the app and its community, interacting with them and being an integrative part of the community. Defines this engagement as: "the level of a customer's cognitive, emotional and behavioral investment in specific brand interactions". This definition clearly shows that the concept of engagement has several facets. If a runner thinks (cognitive) he's a central part of a wider community, this relationship will come with positive emotions (emotional) and will encourage the runner to elicit behavior that will make him an even more integral part of the community.

\section{Brand Loyalty}

Brand loyalty symbolizes a consumer's final relationship and deep level of identification with a brand as the brand gains an exclusive and positive place in the minds of the consumer. Research has shown that brand communities operating on social media can enhance brand loyalty by improving the customer relationship with the brand, the company, other consumers and the products (Laroche, Habibi, \& Richard, 2013) [23]. Brand loyalty is an important concept in marketing, as it has been shown to increase revenues and market share and help companies grow in the marketplace. Based on the definition above, we see that brand loyalty consists of two components, an attitudinal and a behavioral one. The attitudinal component consists of brand commitment, which can be understood as an "enduring desire to maintain a valued relationship" [24]. For this study, we defined brand commitment as the degree of belongingness a person has towards a certain running app.

\section{DIFERENCE AMONG GAMIFICATION ANDCONVENTIONAL} GAME TECHNIQUES 
The biggest significant transformation between the current game and Gamification is in sustainability after "Commitment" and "Reward" have been made. In Gamification, the method of the simplest form of "Commitment" and "Reward", how to present 1 free coffee after collecting 10 stamps, is evolving to actively adopt the user's gaming model: move away from the way of giving and receiving to borrow the game element in the form of a game. The most expansive game element was noted in the concept of the statue using "Engagement" and "Reward". This article aims to analyze the difference between the methods of Gamification not yet familiar and traditional and suggest the Gamification method that will be developed from now on.

\section{POSSIBILITY OF GAMIFICATION}

Although the significant results of the gamification of the business are still unfinished, we expect to see the use of Gamification in more approachable and unusual ways than the facts and design methods. It is also likely that these services will be extensive as existing gaming businesses develop more and better access to games throughout openness and association in various fields. As the progress of Gamification is expected to develop and take advantage of this prospect to the fullest, it is necessary to diversify the Gamification business model. The current proposal of Gamification, which contains of verdict all your answers within what categories the game is fun, is still the only method recommended in the form of marketing. However, as reviewed by many case studies abroad, Gamification is projected to become the expected general trend in games in the future.

\section{CONCLUSION}

In this article, the real cases were analyzed through the identification and research of the concept of Gamification. Furthermore, this article proposes the design elements and the area of use of the gamification model from the analyzed content and compares them and analyzes them with the traditional gambling methods. A method to increase the number of viewers of media and content users through the use of elements of Gamification, which is part of the central mechanism of games, should play a vital role for content companies and content users. Consequently, when a model is developed that covers these elements in the right positions, gamification can be expected to be used in the growth of public knowledge and in the gathering of information not only in the business linked to content. Our results show that running applications are an effective tool for companies, as they have measurable effects on the customer's brand relationship. By combining applications running with social networks, companies have a new and unique way of interacting with their customers. This study is the first step to better understand why people are using running applications.

\section{REFERENCES}

[1] Cowan, L. T., Van Wagenen, S. A., Brown, B. A., Hedin, R. J., Seino-Stephan, Y., Hall, P. C., \&West, J. H. (2012). Apps of steel: are exercise apps providing consumers with realistic expectations? A content analysis of exercise apps for presence of behavior change theory. Health Education \& Behavior, 1090198112452126.

[2] AppBrain (2015) Android Market Stats. Retrieved from www.appbrain.com/stats/

Atienza, A. A., \& Patrick, K. (2011). Mobile health: the killer app for cyberinfrastructure and

[3] Fox, S. (2010, October 19). Mobile health 2010. Pew Internet \& American Life Project. Retrieved from http://www.pewinternet.org/Reports/2010/Mobile-

Health- 2010/Report/Mobile-health-apps.aspx

[4] Research2guidance. (2014). mHealth App Developer Economics: $4^{\text {th }}$ annual study on mHealth app publishing. Retrieved from http://mhealtheconomics.com/mhealthdeveloper- economics-report/

[5] Gagne, M. (2003). Autonomy support and need satisfaction in the motivation and well-being of gymnasts. Journal of Applied Sport Psychology, 15(4), 372-390.

[6] Wilson, D. K., Evans, A. E., Williams, J., Mixon, G., Sirard, J. R., \& Pate, R. (2005). A preliminary test of a student-centered intervention on increasing physical activity in underserved adolescents. Annals of BehavioralMedicine, 30(2), 119-124.

[7] Verhagen, E., \& Bolling, C. (2015). Protecting the health of the@ hlete: how online technology may aid our common goal to prevent injury and illness in sport. British Journal of Sports Medicine, bjsports-2014.

[8] Patrick, K., Griswold, W. G., Raab, F., \& Intille, S. S. (2008). Health and the mobile phone. American journal of preventive medicine, 35(2), 177-181.

[9] Goffman, E. (2002). The presentation of self in everyday life. 1959. Garden City, NY.

[10] Kim, Y., Briley, D. A., \& Ocepek, M. G. (2015). Differential innovation of smartphone and application use by sociodemographics and personality. Computers in Human Behavior, 44, 141-147.

[11] Jahn, B., \& Kunz, W. (2012). How to transform consumers into fans of your brand. Journal of Service Management, 23(3), 344-361. http://dx.doi.org/10.1108/09564231211248444

[12] Bellman, S., Potter, R. F., Treleaven-Hassard, S., Robinson, J. A., \& Varan, D. (2011). The effectiveness of branded mobile phone apps. Journal of interactiveMarketing, 25(4), 191- 200.

[13] World Health Organization (2015a). Global Health Risks: Mortality and Burden of Disease Attributable to Selected Major Risks. Retrieved from http://www.who.int/healthinfo/global_burden_disease/Gl obalHealthRisks_report_full.pdf

[14] World Health Organization (2015b). Physical Inactivity: A Global Public Health Problem. Retrieved from http://www.who.int/mediacentre/factsheets/fs385/en/

[15] Spillers, F., \& Asimakopoulos, S. (2014). Does Social User Experience Improve Motivation for Runners? In Design, User Experience, and Usability. User Experience Design Practice (pp. 358-369). Springer International Publishing.

[16] McAlexander, J. H., Schouten, J. W., \& Koenig, H. F. (2002). Building brand community. Journal of marketing,66(1), 38-54.

[17] Goffman, E. (2002). The presentation of self in everyday life. 1959. Garden City, NY.

[18] Gillison, F. B., Standage, M., \& Skevington, S. M. (2006). Relationships among adolescents' weight perceptions, exercise goals, exercise motivation, quality of life and leisure-time exercise behaviour: a self-determination theory approach. Health Education Research, 21(6), 836-847.

[19] McCrae, R. R., \& Costa Jr, P. T. (1999). A five-factor theory of personality. Handbook of personality: Theory and research, 2, 
$139-153$.

[20] Mechanic, D., \& Hansell, S. (1987). Adolescent competence, psychological well-being, and self- assessed physical health. Journal of Health and Social Behavior, 364-374.

[21] Gnambs, T., \& Batinic, B. (2012). A Personality- Competence Model of Opinion Leadership. Psychology \& Marketing, 29(8), 606-621.

[22] Hollebeek, L. (2011). Exploring customer brand engagement: definition and themes. Journal of strategic Marketing, 19(7), $555-573$
[23] Laroche, M., Habibi, M. R., \& Richard, M. O. (2013). To be or not to be in social media: How brand loyalty is affected by social media? International Journal of Information Management, 33(1), 76-82.

[24] Moorman, C., Zaltman, G., \& Deshpande, R. (1992). Relationships between providers and users of market research: The dynamics of trust. Journal of marketing research, 29(3), 314-328. 